\title{
Numerical Simulation of Near-Surface Wind during a Severe Wind Event in a Complex Terrain by Multisource Data Assimilation and Dynamic Downscaling
}

\author{
De Zhang, ${ }^{1,2}$ Luyuan Chen, ${ }^{2}$ Feimin Zhang $\mathbb{D}^{2},{ }^{2}$ Juan Tan, ${ }^{3}$ and Chenghai Wang $\mathbb{D}^{2}$ \\ ${ }^{1}$ Chinese Academy of Meteorological Sciences, Beijing 100081, China \\ ${ }^{2}$ Research and Development Center of Earth System Model (RDCM), College of Atmospheric Sciences, Lanzhou University, \\ Key Laboratory for Arid Climatic Change and Disaster Reduction of Gansu Province, Lanzhou 730000, China \\ ${ }^{3}$ Institute for Development and Programme Design, China Meteorological Administration, Beijing 100081, China
}

Correspondence should be addressed to Feimin Zhang; zfm@lzu.edu.cn and Chenghai Wang; wch@lzu.edu.cn

Received 14 January 2020; Revised 4 November 2020; Accepted 28 November 2020; Published 30 December 2020

Academic Editor: Nir Y. Krakauer

Copyright (c) 2020 De Zhang et al. This is an open access article distributed under the Creative Commons Attribution License, which permits unrestricted use, distribution, and reproduction in any medium, provided the original work is properly cited.

\begin{abstract}
Accurate forecast and simulation of near-surface wind is a great challenge for numerical weather prediction models due to the significant transient and intermittent nature of near-surface wind. Based on the analyses of the impact of assimilating in situ and Advanced Tiros Operational Vertical Sounder (ATOVS) satellite radiance data on the simulation of near-surface wind during a severe wind event, using the new generation mesoscale Weather Research and Forecasting (WRF) model and its three-dimensional variational (3DVAR) data assimilation system, the dynamic downscaling of near-surface wind is further investigated by coupling the microscale California Meteorological (CALMET) model with the WRF and its 3DVAR system. Results indicate that assimilating in situ and ATOVS radiance observations strengthens the airflow across the Alataw valley and triggers the downward transport of momentum from the upper atmosphere in the downstream area of the valley in the initial conditions, thus improving near-surface wind simulations. Further investigations indicate that the CALMET model provides more refined microtopographic structures than the WRF model in the vicinity of the wind towers. Although using the CALMET model achieves the best simulation of near-surface wind through dynamic downscaling of the output from the WRF and its 3DVAR assimilation, the simulation improvements of near-surface wind speed are mainly within $1 \mathrm{~m} \mathrm{~s}^{-1}$. Specifically, the mean improvement proportions of near-surface wind speed are $64.8 \%$ for the whole simulation period, $58.7 \%$ for the severe wind period, $68.3 \%$ for the severe wind decay period, and $75.4 \%$ for the weak wind period. The observed near-surface wind directions in the weak wind conditions are better simulated in the coupled model with CALMET downscaling than in the WRF and its 3DVAR system. It is concluded that the simulation improvements of CALMET downscaling are distinct when near-surface winds are weak, and the downscaling effects are mainly manifested in the simulation of near-surface wind directions.
\end{abstract}

\section{Introduction}

Severe wind, which is defined as the instantaneous wind speed reaches or exceeds $17 \mathrm{~m} \mathrm{~s}^{-1}$, is a frequently experienced extreme weather event in arid and semi-arid regions of Northwest China [1]. Improving the forecast accuracy of near-surface wind (wind speed and wind direction), especially over a complex terrain, is very important for wind farm safety and air pollutant prediction etc. Such forecasting, however, remains a major challenge for numerical weather prediction models $[2,3]$.
Numerical simulation techniques are widely used in forecasting near-surface wind. Results of Wang et al. [3] indicated that the mesoscale Weather Research and Forecasting (WRF) model produced a better simulation of nearsurface wind speed in April when surface diabatic heating is stronger, compared with January. The case study based on WRF simulation showed that the downward momentum transport caused by atmospheric baroclinicity and local atmospheric instability induced by surface diabatic heating, are closely related to severe wind in North-west China [4]. 
Examination of near-surface wind simulation over a complex terrain indicated an inverse relationship between the observed and simulated wind speeds [5]. Simulation of lowlevel jets in west Texas and south Kansas in the United States using the WRF model showed that, although the WRF model characterises low-level jets, its simulation performance on intensity variations remains limited [6].

As an important approach to improve the initial conditions of the numerical models, data assimilation methods have recently been gaining attention for prediction of nearsurface winds. For instance, numerical simulations have demonstrated that assimilation of in situ near-surface and sounding observations using the Newton relaxation (Nudging) techniques improve near-surface wind simulation [7-9]. Numerical simulation based on the WRF model and the 3DVAR assimilation system suggested that assimilation of in situ near-surface and sounding and ATOVS satellite radiance observations can effectively reduce the simulation biases of near-surface wind [10].

So far, the horizontal resolution of terrain, land use, and vegetation cover data in current mesoscale numerical models like the WRF is still coarse. Due to the transient and intermittent nature of near-surface winds, detailed dynamic structures of near-surface wind evolution dominated by local microtopography may not be accurately captured and described by mesoscale numerical models, thus degrading near-surface wind simulations. Therefore, dynamic downscaling of mesoscale model results using a microscale meteorological model (has more refined underlying land surface state) should be an effective approach to improve the simulation accuracy of near-surface wind. Recent studies showed that dynamic downscaling of nearsurface wind using the microscale California Meteorological (CALMET) model revealed additional terrain-related structures for near-surface wind simulation $[11,12]$.

The studies reviewed showed successful application of the mesoscale WRF model, assimilation techniques, and microscale CALMET model in the simulation of nearsurface wind. Combining the advantages of these models and techniques could offer an alternative approach to improve near-surface wind simulation. For instance, the dynamic downscaling effects of local microtopography in the CALMET model largely depend on the initial and boundary conditions of the input model. The outputs from the 3DVAR assimilation remedy this limitation because of the improved simulation results. On this basis, this study aims to (1) investigate the impacts of in situ and ATOVS radiance data assimilation on the simulation of a severe wind event and (2) examine the dynamic downscaling effects of local microtopography in the CALMET model, especially when near-surface wind is strong and weak. These will be done by numerical simulation of a severe wind episode that happened in the Alataw valley and its vicinity area. This area is focused because it is among the areas in China that most frequently experience severe wind [1] and is also an important wind energy base in China and hosts the railway crossings of the second Eurasian continental bridge.

\section{Model Description, Data, Experiment Design, and Methods}

The Advanced Research WRF (ARW) model and its 3DVAR techniques [13] are employed for the simulations. The simulations involve three two-way nested domains (Figure 1(a)) with horizontal grid resolutions of 45, 15, and $5 \mathrm{~km}$, respectively. The Lambert-conformal map projection is used in the simulation. The innermost model domain focuses on the Alataw valley and its vicinity. In this study, the terrain-following vertical coordinate is utilized in the WRF model, with 40 vertical levels in total. Considering nearsurface wind observations are at $70 \mathrm{~m}$ above the ground level, the default terrain-following vertical levels ( $\eta$ levels) are modified manually so that the height of the second $\eta$ level $(\eta=0.997)$ from ground surface is close to $70 \mathrm{~m}$. Although $\eta$ level in a terrain-following coordinate depends on pressure at the bottom and the different model level, the height of each $\eta$ level from the ground surface could vary with the integration. In our study, however, the height of the second $\eta$ level from the ground surface in the three wind towers is close to $70 \mathrm{~m}$, without evident fluctuation during the whole integration (not shown). The physical parameterizations include the KainFritsch cumulus scheme (for " $\mathrm{d} 01$ " and "d02" only) [14], the Purdue Lin microphysics scheme [15], the Rapid Radiative Transfer Model for longwave radiation [16], the Dudhia scheme for shortwave radiation [17], the YSU scheme for boundary layer processes [18], and $\mathrm{NOAH}$ scheme for land surface processes [19].

The assimilation of in situ and ATOVS radiance observations is conducted in a cycling mode (warm start) for each nested domain using 3DVAR techniques; detailed assimilation method can be found in Zhang et al. [10]. The background error covariance matrix used in data assimilation is separately generated for each nested domain based on the National Meteorological Centre (NMC) method $[13,20]$; using the WRF simulations at 24 and 12 hours forced by GFS data described below, the simulation samples of the three months are from September 01, 2010, to November 31, 2010. The radiative transfer model used in the 3DVAR assimilation system is the Community Radiative Transfer Model (CRTM 2.02).

Since the near-surface wind simulation is very sensitive to the local effects caused by terrain and land surface heterogeneity, the CALMET model, which is a three-dimensional microscale meteorological diagnostic model [21], is further coupled with WRF and its 3DVAR assimilation in an off-line mode. CALMET is a mass conserving model that simulates hourly wind fields on a three-dimensional gridded domain, including mixing height, surface characteristics, and dispersion properties. Over land, the boundary layer scheme in CALMET is parameterized based on the energy balance of Holtslag and van Ulden [22] to compute hourly gridded fields of the heat flux, surface friction velocity, MoninObukhov length, and convective velocity scale. In this study, the calculations of near-surface wind in CALMET are as follows: (1) model output of the simulated near-surface wind in the innermost domain from WRF and its 3DVAR 




(a)

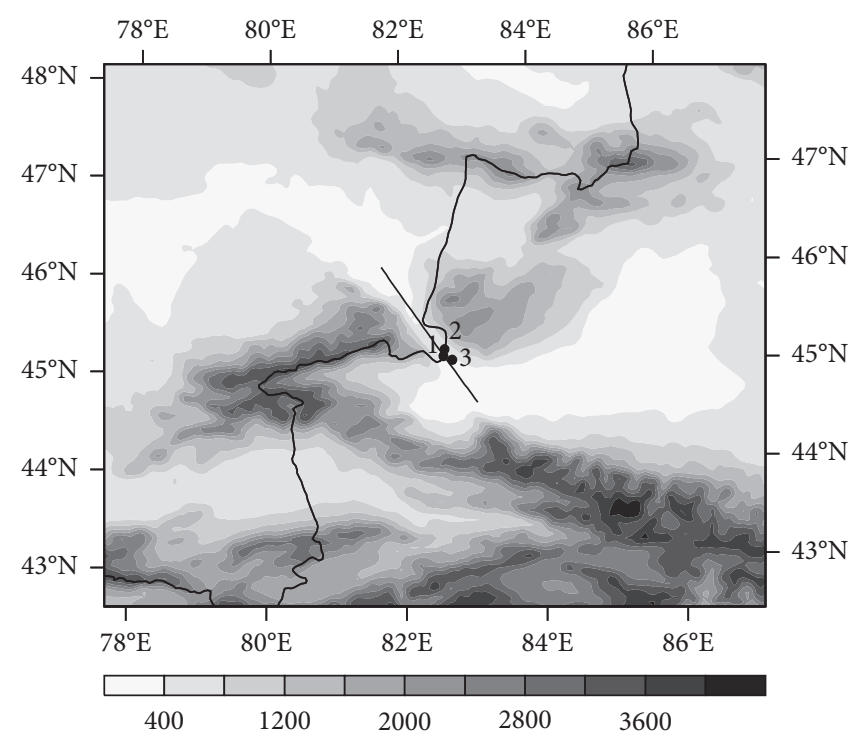

(b)

FIGURE 1: Configuration of the (a) three nested WRF simulation domains in Lambert conformal projection and (b) terrain height (shaded, unit: $\mathrm{m}$ in the innermost domain (d03)). The black dots in each figure panel denote the locations of wind towers near the Alataw valley. The black solid line in (b), which goes through the Alataw valley, will be used to draw the vertical cross section (Figure 3).

assimilation is served as initial guess to drive CALMET model, and the adjustment for terrain, slope flows, and terrain blocking effects is then conducted to refine the local near-surface wind affected by local terrain and land surface heterogeneity; (2) the kinematic effects of the terrain on the horizontal near-surface wind are adjusted by applying a divergence minimization procedure. Three experiments are conducted in this study:

(1) WRF: the default configuration of the WRF model as described above.

(2) WRF + 3DVAR: same as WRF, but involving in situ near-surface, sounding, and ATOVS radiance data assimilation in the cycling assimilation mode for each nested domain.

(3) $\mathrm{WRF}+3 \mathrm{DVAR}+\mathrm{CALMET}$ : same as the WRF + 3DVAR, but is coupled with dynamic downscaling using CALMET as described above. Detailed configurations of CALMET model can be seen in Table 1.

The initial and boundary conditions used for driving WRF model are obtained from the Global Forecasting System (GFS) data provided by the National Centres for Environmental Prediction (NCEP), with temporal and horizontal spatial resolution of $3 \mathrm{~h}$ and $1.0^{\circ} \times 1.0^{\circ}$, respectively. A 72-hour simulation of WRF is conducted with the initial time at 1200 UTC 20 Oct 2010. The cycling 3DVAR assimilation starts at 1800 UTC 19 Oct 2010 and ends at 1200 UTC 20 Oct 2010, with a 6-hour assimilation window; in other words, the total assimilation period is $18 \mathrm{~h}$ and data assimilation is conducted every 6 hours. The first 12 hours before 0000 UTC 21 Oct 2010 are regarded as model spin-up period and are not analyzed in this study.

Geopotential height, temperature, and sea level pressure data, which are used to analyze the synoptic system before and during the severe wind event (Figure 2), come from the ERA5 reanalysis (https://cds.climate.copernicus.eu/ \#!/home, https://doi.org/10.24381/cds.adbb2d47) produced by the European Centre for Medium-Range Weather Forecasting (ECMWF), with a horizontal resolution of $0.25^{\circ} \times 0.25^{\circ}$. The in situ near-surface and sounding observations with temporal resolution of $3 \mathrm{~h}$ and $12 \mathrm{~h}$, respectively, which are used in 3DVAR assimilation and Figures 2(e) and 2(f), come from China Meteorological Administration (CMA). The radiance data for 3DVAR assimilation include microwave temperature detectors (AMSU-A) and microwave humidity detectors (AMSU-B) on NOAA17/16/18 satellites. The thinning mesh of the satellite radiance data is $120 \mathrm{~km}$, and the exact satellite channels used in the assimilation are 5, 6, 7, 8, and 9 for AMSU-A and 3, 4, and 5 for AMSU-B. Figure 1(b) shows the locations of the three near-surface wind observation towers (tower $1: 45.18^{\circ} \mathrm{N}$ and $82.61^{\circ} \mathrm{E}$; tower 2: $45.25^{\circ} \mathrm{N}$ and $82.63^{\circ}$ $\mathrm{E}$; tower $3: 45.14^{\circ} \mathrm{N}$ and $82.74^{\circ} \mathrm{E}$ ) in the downstream area of the Alataw valley. The observations from wind towers are at $70 \mathrm{~m}$ above the ground level, with a temporal resolution of $10 \mathrm{~min}$. Note that the observed near-surface wind from the above three towers are not assimilated, and they are only used to validate the simulation results. Since the position of the simulation results changes when introducing the extra resolution in the CALMET simulation, the bilinear interpolation method is employed to obtain the simulation results from the innermost model domain. 
TABLE 1: Configurations of the CALMET model in the WRF + 3DVAR + CALMET experiment.

\begin{tabular}{lc}
\hline Model parameter & Value \\
\hline Grid numbers & $250 \times 220$ \\
Grid spacing & $100 \mathrm{~m}$ \\
Map projection & Universal transverse mercator (UTM) \\
Terrain data & SRTM3 $(\sim 90 \mathrm{~m})$ \\
Land cover land use & GLCC database $(\sim 900 \mathrm{~m})$ \\
Initial and boundary conditions & WRF + 3DVAR output from the innermost simulation domain \\
\hline
\end{tabular}

The following statistics are used to quantify the differences among the experiments:

Mean relative error (MRE):

$$
\operatorname{MRE}=\frac{1}{n} \sum_{i=1}^{n} \frac{\left(P_{i}-O_{i}\right)}{O_{i}} .
$$

Root-mean-squared error (RMSE):

$$
\text { RMSE }=\sqrt{\frac{1}{n} \sum_{i=1}^{n}\left(O_{i}-P_{i}\right)^{2} .}
$$

Index of agreement (IA):

$$
\mathrm{IA}=1-\frac{\sum_{i=1}^{N}\left(P_{i}-O_{i}\right)^{2}}{\sum_{i=1}^{N}\left(\left|P_{i}-\bar{O}\right|+\left|O_{i}-\bar{O}\right|\right)^{2}}
$$

where $\bar{O}$ and $\bar{P}$ represent the averaged values for observations and simulations, respectively. The observed and simulated values at each time are represented by $O_{i}$ and $P_{i}$, respectively. Better simulations are indicated if MRE and RMSE are smaller, and IA is closer to 1.0.

\section{Description of the Severe Wind Event}

A severe wind event occurred in 21-23 Oct 2010 near the Alataw valley, and its vicinity is focused in this study. The instant near-surface wind speeds exceed $17 \mathrm{~m} \mathrm{~s}^{-1}$ recorded at the three wind towers lasting above 24 hours (Figure 7).

Figures 2(a) and 2(b) show the geopotential height and temperature at $500 \mathrm{hPa}$ in 1200 UTC 20 Oct 2010 (before the severe wind, hereafter) and at 0000 UTC 21 Oct 2010 (during the severe wind, hereafter). Results indicate that, before the severe wind, a deep trough associated with a closed cold centre exists near the Caspian-Balkhash Lake, and the cold advections in the rear of the trough and warm advection in the front of the trough are evident. During the severe wind, the trough develops and moves eastward to the vicinity of Balkhash Lake and the horizontal trough turns to vertical and a closed low-pressure centre coincides with the cold centre, suggesting that the trough develops rapidly and forms a cyclone system with a cold centre. Figures 2(c)-2(f) show the sea level pressure and in situ near-surface temperature in the vicinity of the Alataw valley. Results show that a closed and clod high pressure centre exists east of the Balkhash Lake before the severe wind and it moves into the Alataw valley and its vicinity during the severe wind. In other words, the cold air activities along with a high-pressure region in the upstream area of the Alataw valley provide fair conditions for the onset of severe wind event.

\section{Simulation Results}

4.1. Impact of Data Assimilation on the Simulation of Near-Surface Wind. Figure 4 displays the distribution of in situ sounding observations for each 3DVAR assimilation cycle. Results indicate that the in situ sounding observations are mostly assimilated. Due to the large difference in height between the model terrain and the actual station terrain over the Northwest China, the in situ near-surface observations, however, are barely used in the 3DVAR assimilation system (not shown) [23]. Previous studies have indicated that adding terrain error representativeness to the surface observation error or reducing temperature observation via the temperature lapse rate from actual station elevation to model terrain height or using the Ensemble Kalman Filter method are effective approaches to assimilate near-surface observations $[24,25]$. Overall, the in situ sounding observations are the primary data that contribute to the $3 \mathrm{DVAR}$ assimilation system.

Figure 5 exhibits the distribution of ATOVS radiance data for each assimilation cycle. Results indicate that satellite radiance data provide abundant observation information to the 3DVAR system, especially in the upstream area of the Alataw valley and its environs. These data also effectively compensate the in situ sounding observation gap in the second assimilation cycle at 0600 UTC 20 Oct 2010. Therefore, the ATOVS satellite radiance data provided dependable observation information for the 3DVAR system.

Figure 6 show the near-surface wind speed at $70 \mathrm{~m}$ and air temperature for WRF, WRF + 3DVAR, and their assimilation increments (defined as the difference of the meteorological quantity after and before the assimilation) in the innermost simulation domain at the analysis (initial) time (1200 UTC 20 Oct 2010). Results indicate that, compared to the WRF simulation, temperature contrast between the upstream and the downstream areas of the Alataw valley becomes evident after the assimilation. The cold air attains the Alataw valley in the WRF + 3DVAR experiment but not in the WRF experiment. In addition, the northwestern nearsurface wind in the Alataw valley and its upstream area are more distinct in WRF + 3DVAR experiment than in WRF experiment, suggesting that the airflow across the valley has been established after assimilation. The assimilation increments (Figure 6(c)) further show that cold air reaches the Alataw valley, with an obvious velocity stream across the 


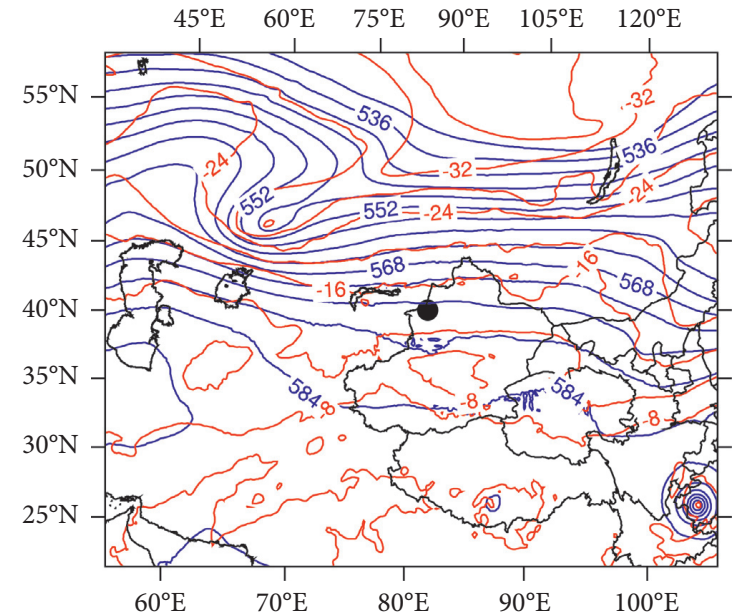

(a)

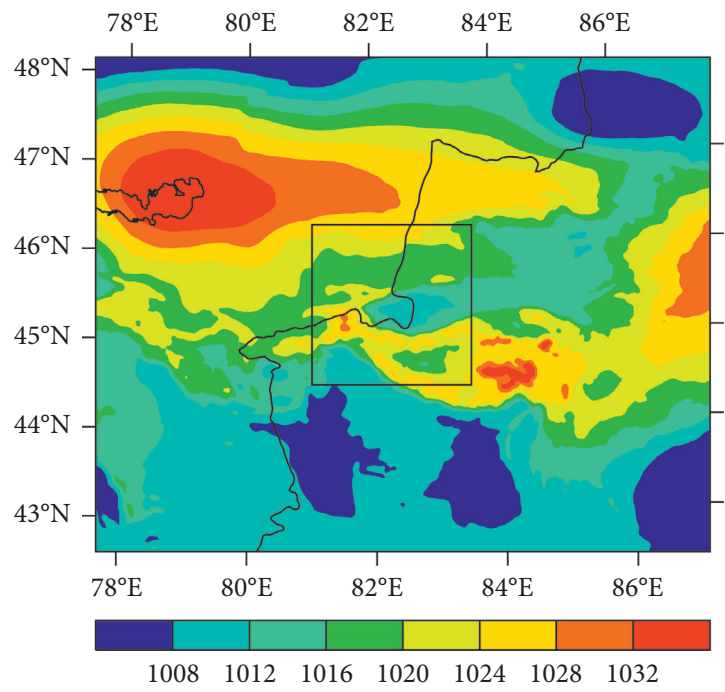

(c)

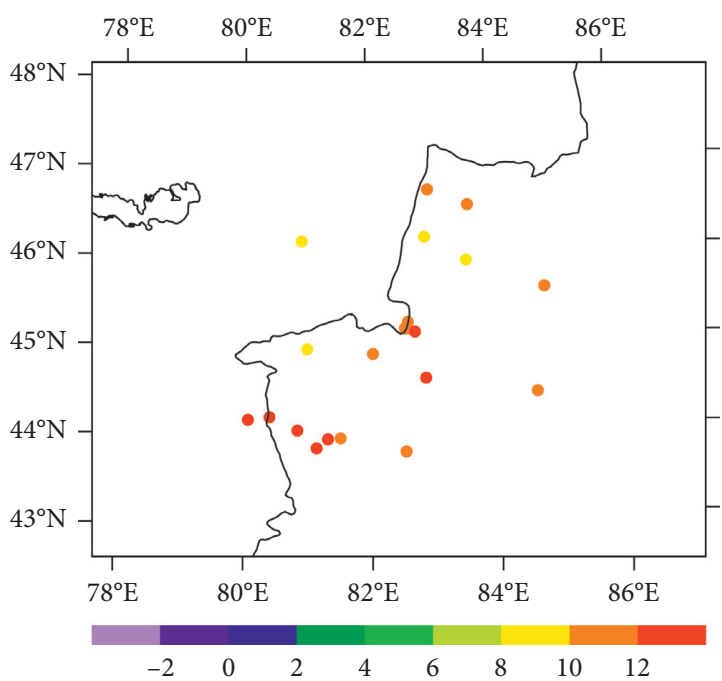

(e)



(b)

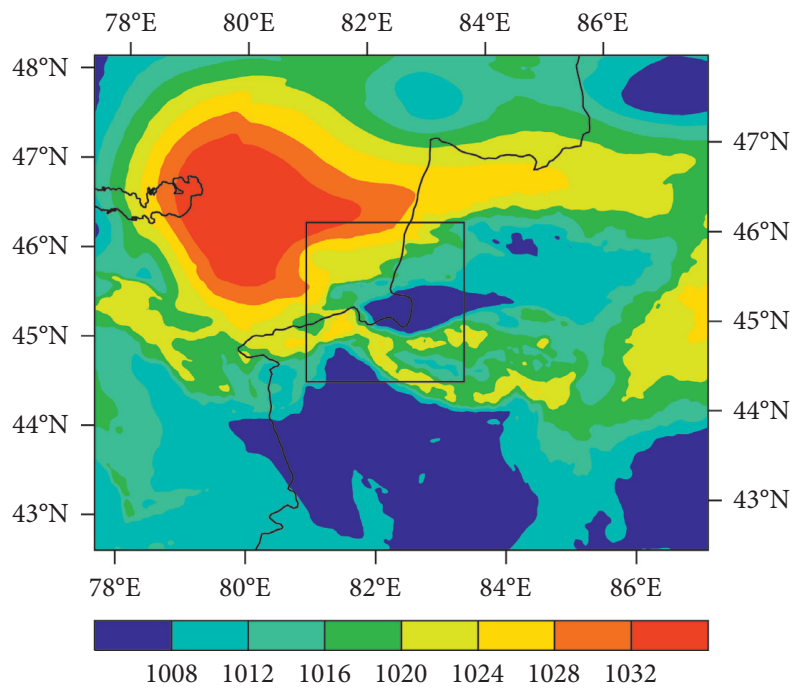

(d)



(f)

Figure 2: (a, b) Geopotential height (blue contours, unit: $\left.\times 10^{-1} \mathrm{~m}\right)$ and temperature (red contours, unit: $\left.{ }^{\circ} \mathrm{C}\right)$ at $500 \mathrm{hPa} ;((\mathrm{c}),(\mathrm{d}))$ sea level pressure (shaded, unit: hPa); ((e), (f)) the in situ observed air temperature (coloured dots, unit: $\left.{ }^{\circ} \mathrm{C}\right)$ at ((a), (c), (e)) 1200 UTC 20 Oct 2010 (before the severe wind) and ((b), (d), (f)) 0000 UTC 21 Oct 2010 (during the severe wind). The black dots in ((a), (b)) denote the locations of wind towers near the Alataw valley. The black boxes in $((\mathrm{c}),(\mathrm{d}))$ show the Alataw valley and its vicinity areas. 


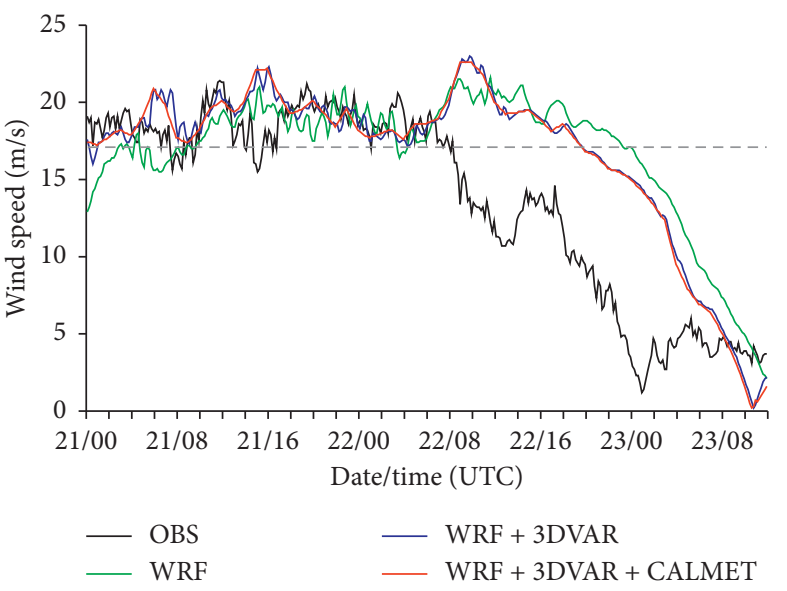

(a)

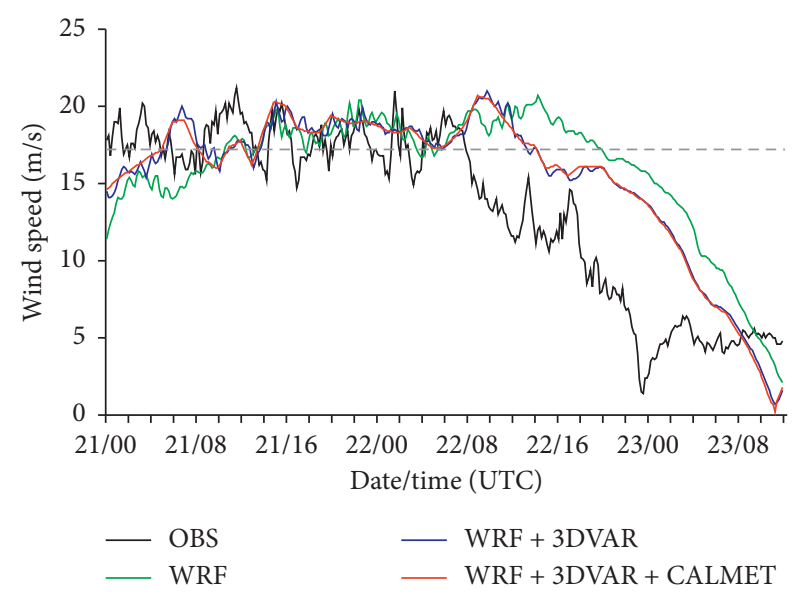

(b)

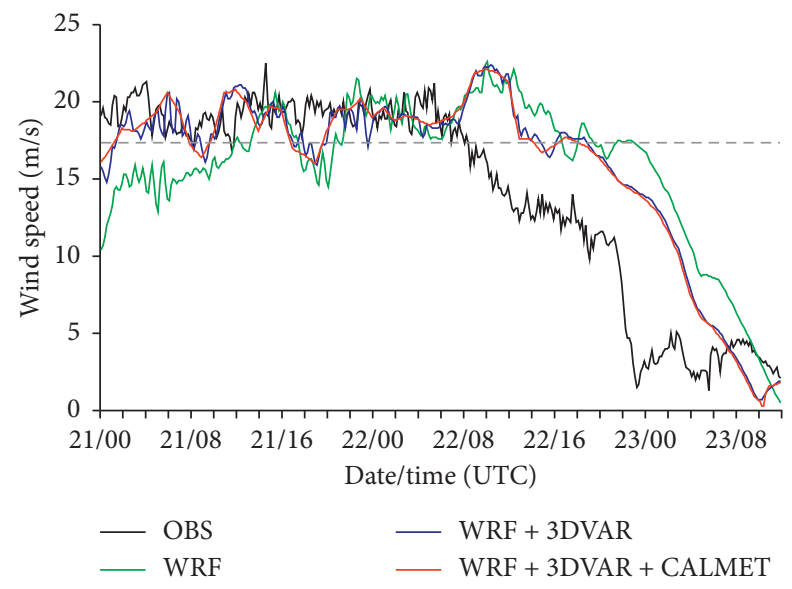

(c)

Figure 3: Times series of observed and simulated near-surface wind speed (unit: $\mathrm{m} \mathrm{s}^{-1}$ ) in different numerical experiments at $70 \mathrm{~m}$ for (a) tower 1 , (b) tower 2, and (c) tower 3. The severe wind threshold of $17 \mathrm{~m} \mathrm{~s}^{-1}$ is denoted by the grey-dashed lines

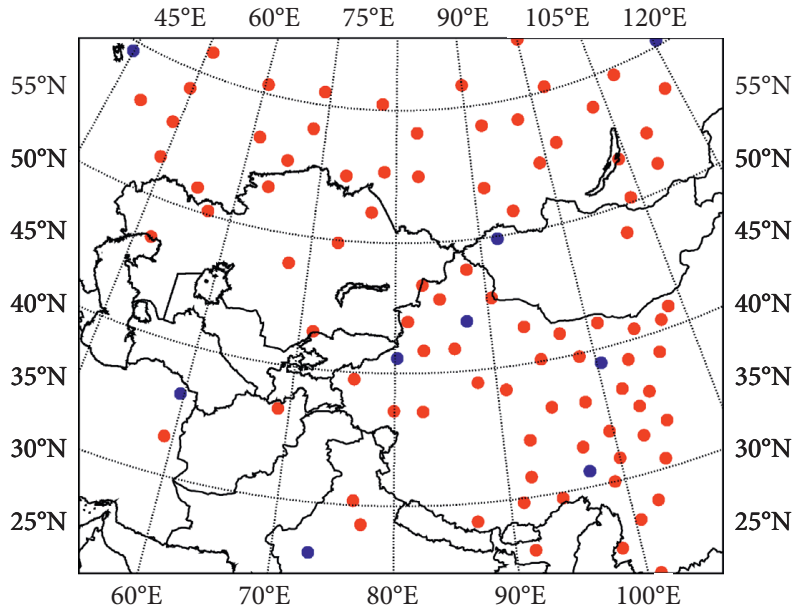

(a)

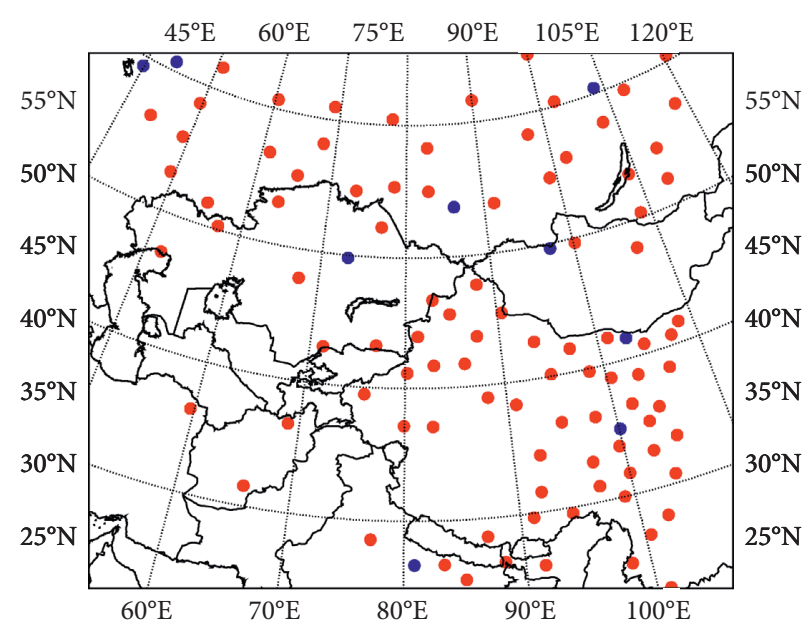

(b)

FIGURE 4: The spatial distribution of in situ sounding observations in the WRF + 3DVAR experiment at (a) 0000 UTC 20 Oct 2010 and (b) 1200 UTC 20 Oct 2010. The red dots represent the distributions of in situ soundings that pass the quality control and are absorbed/used in the 3DVAR assimilation system. The blue dots represent the distributions of in situ soundings that do not pass the quality control. No in situ soundings are available at 0600 UTC 20 Oct 2010. 


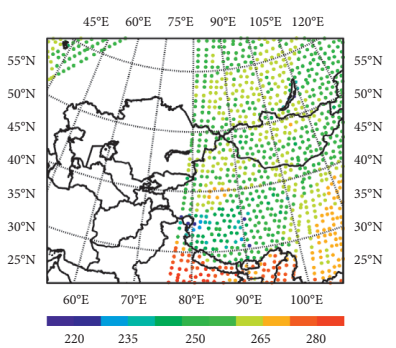

(a)



(e)

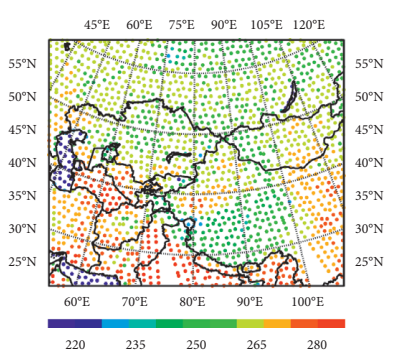

(i)

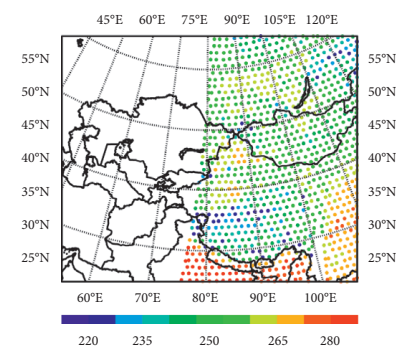

(b)

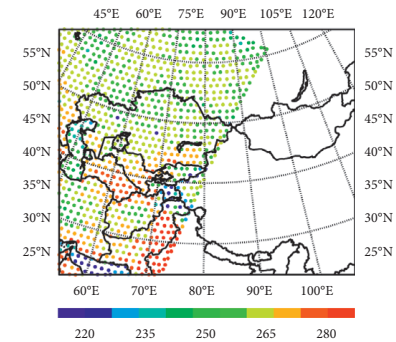

(f)

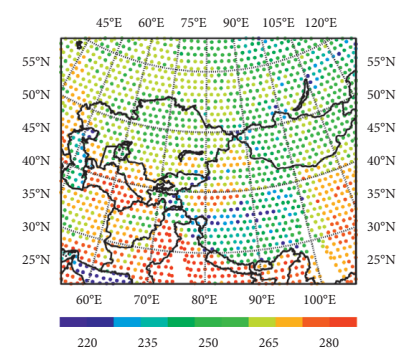

(j)

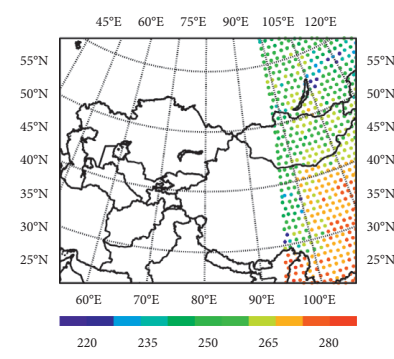

(c)

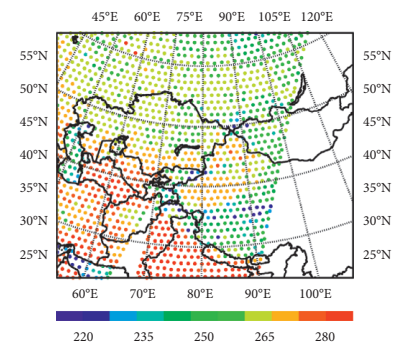

(g)

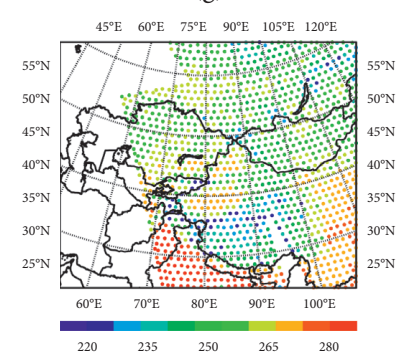

(k)

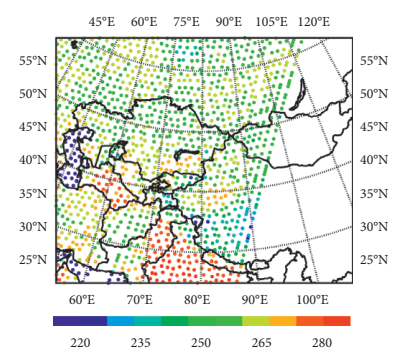

(d)



(h)

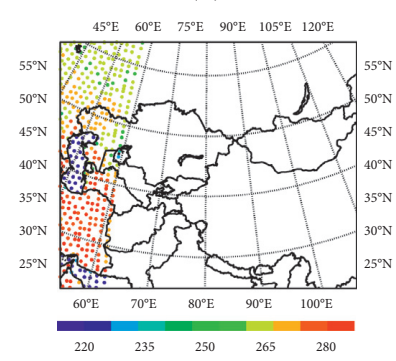

(1)

FIGURE 5: The observed brightness temperatures (coloured dots, unit: K) of ATOVS radiance that are derived from different satellites and sensors at ((a)-(d)) 0000 UTC 20 Oct 2010, ((e)-(h)) 0600 UTC 20 Oct 2010, and ((i)-(l)) 1200 UTC 20 Oct 2010. ((a), (e), (i)) NOAA16AMSUA; ((b), (f), (j)) NOAA16-AMSUB; ((c), (g), (k)) NOAA17-AMSUB; ((d), (h), (l)) NOAA18-AMSUA.

valley. These results indicate that assimilation experiment strengthens the temperature contrast between the upstream and the downstream regions of Alataw valley and establishes an obvious airflow through the valley in the initial conditions, compared to the default WRF simulation.

Figure 7 shows the cross section of the potential temperature, wind vector, and divergence near the Alataw valley (the black line in Figure 1(b)) in the lower atmosphere. Results indicate that without assimilation, the cold front misses the Alataw valley, with an unobvious temperature contrast between the upstream and the downstream regions of the Alataw valley; besides, in the area downstream of the Alataw valley near the observation wind towers, the atmospheric convergence/divergence and their vertical contract are weak, without evident vertical motions (white box in the figure). After assimilation, however, it is clear that the cold front has arrived in the Alataw valley, with the strengthened temperature contrast between the upstream and the downstream regions of the Alataw valley; in the area downstream of the Alataw valley near the observation wind towers, the divergence in the lower atmosphere (500 1500 m above the ground level) and the convergence in the upper atmosphere (1500 2500 $\mathrm{m}$ above the ground level) become stronger, with evident downward vertical motions (white box in the figure). This scenario could trigger the momentum from the upper atmosphere transport downward to the lower atmosphere due to the subsidence movement and, therefore, is conducive to the increase of near-surface wind. These features can be further seen in assimilation increment in Figure 7(c). These results indicate that assimilation experiment produces an obvious downward transport of momentum from the upper atmosphere in the downstream area of the Alataw valley in the initial conditions, compared to the default WRF simulation.

To summary, assimilation of in situ and ATOVS radiance observations provides favourable initial dynamic and thermodynamic conditions that are conducive to the development of severe wind. These effects are manifested mainly by the obvious airflow across the valley and downward transport of momentum from the upper atmosphere in the downstream area of the valley.

Figure 3 compares the time-series of the observed and simulated near-surface wind speed at $70 \mathrm{~m}$ in the three wind towers. Compared to the observations, the WRF experiment mostly underestimates the near-surface wind during the severe wind period (0000 UTC 21 Oct to 0800 UTC 22 Oct), 


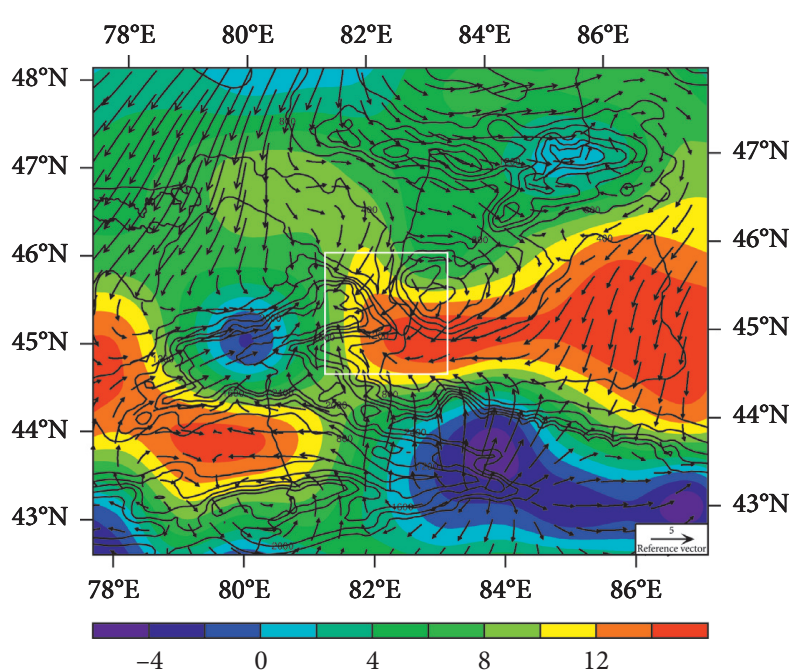

(a)

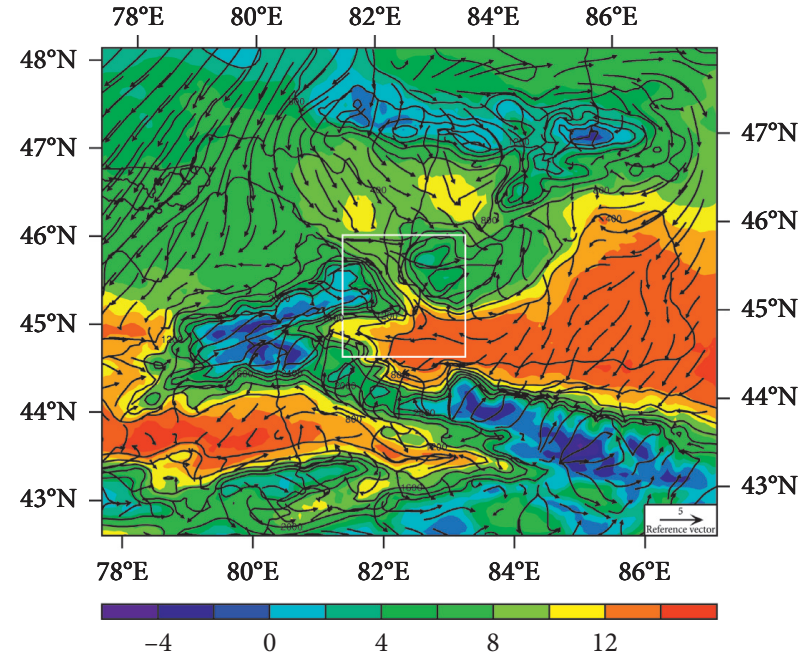

(b)

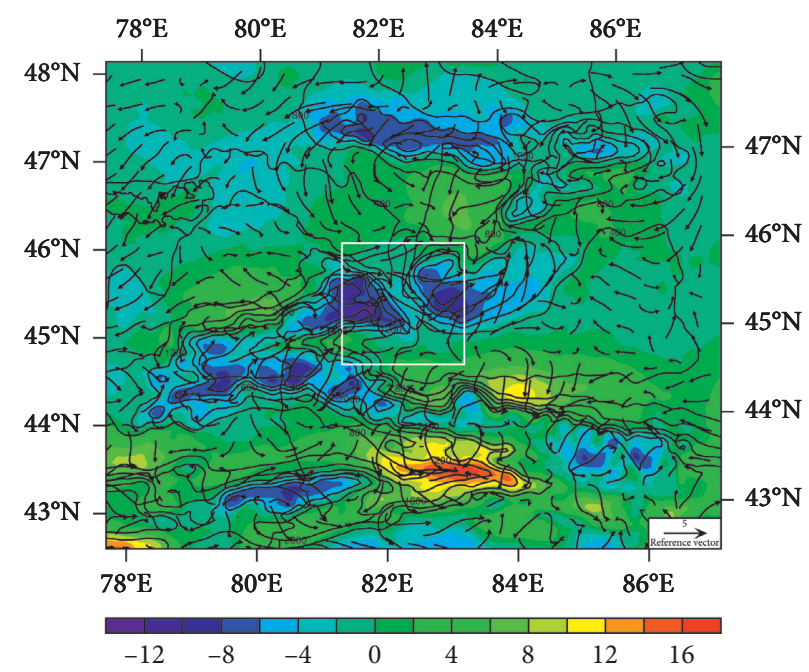

(c)

Figure 6: Near-surface wind at $70 \mathrm{~m}$ above the ground level (vectors, unit: $\mathrm{m} \mathrm{s}^{-1}$ ) and air temperature (shaded, unit: ${ }^{\circ} \mathrm{C}$ ) at $1200 \mathrm{UTC} 20$ Oct 2010. (a) WRF; (b) WRF + 3DVAR; (c) the increment between WRF + 3DVAR and WRF (WRF + 3DVAR minus WRF). The white boxes show the Alataw valley and its vicinity areas.

while the WRF + 3DVAR experiment produces better results. Although all experiments overestimate the near-surface wind during the severe wind decay period (0800 UTC 22 Oct to 2200 UTC 22 Oct) and the weak wind period (2200 UTC 22 Oct to 1200 UTC 23 Oct), simulations involving the WRF + 3DVAR, however, are still superior to those of the WRF experiment. Therefore, assimilation of in situ and ATOVS radiance observations can improve the simulation performance of near-surface wind speed.

4.2. Dynamic Downscaling Effects on Near-Surface Wind Simulation. To further investigate how refined microtopography affects and contributes to the near-surface wind simulation, simulation performances of the WRF + 3DVAR + CALMET experiment are further investigated. Results of Table 1 show that the terrain resolution in the CALMET model is approximately $90 \mathrm{~m}$ and is more detailed than in the WRF model $(\sim 900 \mathrm{~m})$, and this could be important for near-surface wind simulation.

A comparison of simulated near-surface wind speed between WRF + 3DVAR and WRF + 3DVAR + CALMET experiments is displayed in Figure 3 and Table 2. Results show that the downscaling simulation in WRF + 3DVAR + CALMET presents similar near-surface wind speed to the WRF + 3DVAR simulation; they are clearly much better than the default WRF simulation. Figure 8 compares the proportion distribution regarding the difference of absolute error of near-surface wind speed simulation between WRF + 3DVAR + CALMET and $\mathrm{WRF}+3 \mathrm{DVAR}$; negative values represent smaller simulation biases in WRF + 3DVAR + CALMET than in WRF + 3DVAR. In particular, comparison is conducted for different simulation periods such as the whole simulation period (0000 UTC 21 Oct 


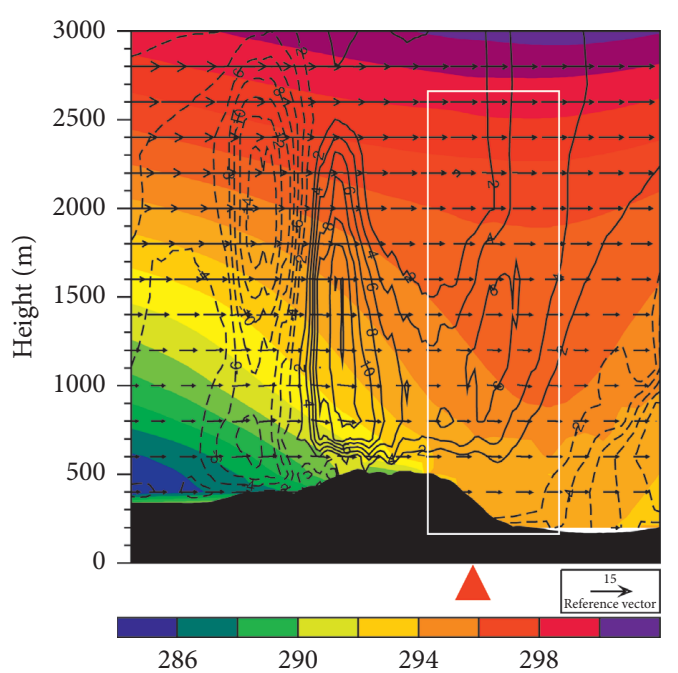

(a)

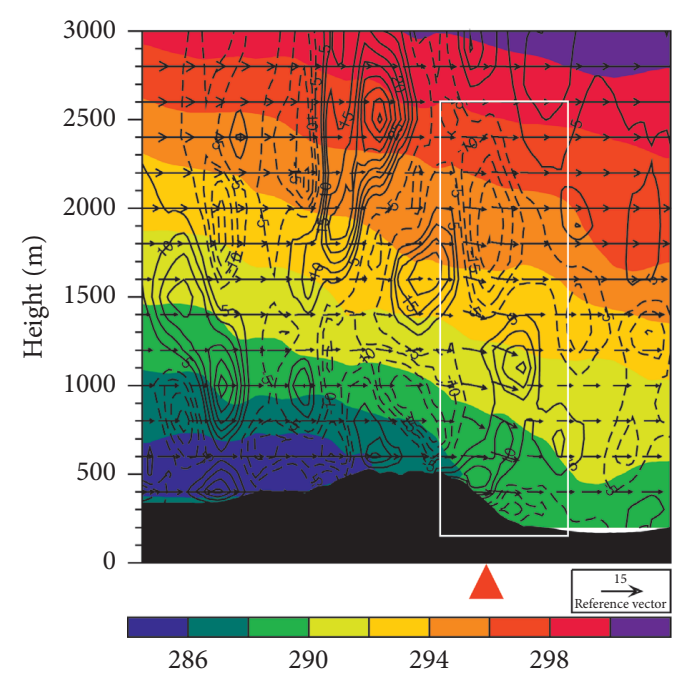

(b)

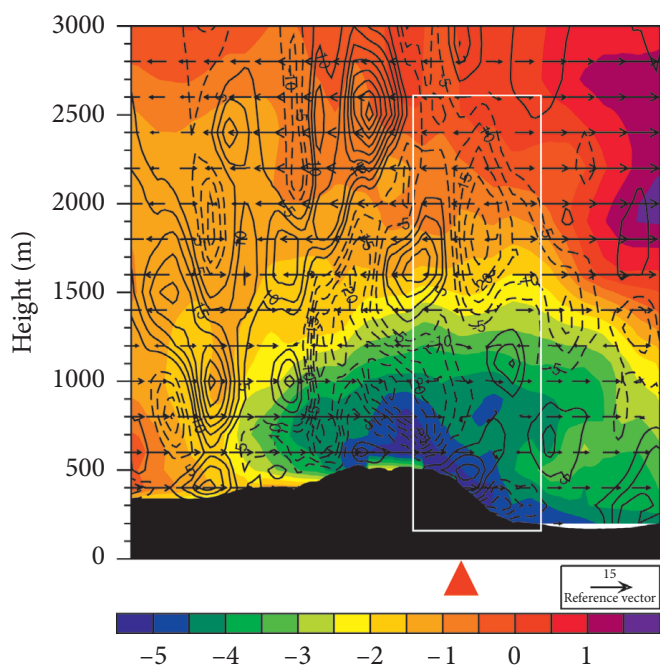

(c)

Figure 7: The vertical cross section (its position is shown as black solid line in Figure 1(b)) of potential temperature (shaded, unit: K, wind composed by horizontal and vertical velocity (vectors, unit of vertical velocity is $\times 10^{-2} \mathrm{~m} \mathrm{~s}^{-1}$ ) and divergence (contours, unit: $\left.\times 10^{-5} \mathrm{~s}^{-1}\right)$ at 1200 UTC 20 Oct 2010. (a) WRF; (b) WRF + 3DVAR; (c) the increment between WRF + 3DVAR and WRF (WRF + 3DVAR minus WRF). The white boxes show the downstream regions of the Alataw valley near the three wind towers. The red triangles denote the approximate location of the three wind towers as shown in Figure 1. The black-shaded color denotes the terrain height across the Alataw valley.

to 1200 UTC 23 Oct), the severe wind period (0000 UTC 21 Oct to 0800 UTC $22 \mathrm{Oct}$ ), the severe wind decay period (0800 UTC 22 Oct to 2200 UTC 22 Oct), and the weak wind period (2200 UTC 22 Oct to 1200 UTC 23 Oct). Results indicate that CALMET downscaling overall improves near-surface wind speed simulation for different wind periods, the mean improvement proportions of near-surface wind speed are $64.8 \%$ for the whole simulation period, $58.7 \%$ for the severe wind period, $68.3 \%$ for the severe wind decay period, and $75.4 \%$ for the weak wind period. These results suggest that the simulation improvements of CALMET downscaling are distinct when near-surface winds are weak. Meanwhile, compared to $\mathrm{WRF}+3 \mathrm{DVAR}$, the simulation improvements of near-surface wind speed in WRF + 3DVAR + CALMET are mainly within $1 \mathrm{~m} \mathrm{~s}^{-1}$.
To summarise, CALMET downscaling can reduce the overall simulation error of near-surface wind speeds, and its effects become distinct when near-surface wind becomes weak.

Since wind is composed of wind speed and wind direction, it is also imperative to investigate how and to what extent CALMET downscaling can contribute to the simulation of near-surface wind directions. Figure 9 compares the simulation of near-surface wind directions between the observations and the simulations for the whole simulation period. Results indicate that the observed dominant wind directions of Tower 2 range from north-northwest (NNW) to northwest (NW); they are not captured by any experiment. For Towers 1 and 3, the observed dominant wind directions are better simulated by CALMET downscaling, 
TABLE 2: Statistic results of near-surface wind speed simulations in different experiments averaged for the three wind towers.

\begin{tabular}{|c|c|c|c|c|}
\hline & & WRF & WRF + 3DVAR & WRF + 3DVAR + CALMET \\
\hline \multirow{3}{*}{ The severe wind period (0000 UTC 21 Oct to 0800 UTC 22 Oct) } & IA & 0.37 & 0.32 & 0.33 \\
\hline & MRE (\%) & 10.70 & 8.03 & 7.87 \\
\hline & $\begin{array}{c}\text { RMSE } \\
\left(\mathrm{m} \mathrm{s}^{-1}\right)\end{array}$ & 2.13 & 1.86 & 1.82 \\
\hline \multirow{3}{*}{$\begin{array}{l}\text { The severe wind decay period ( } 0800 \text { UTC } 22 \text { Oct to } 2200 \text { UTC } 22 \\
\text { Oct) }\end{array}$} & IA & 0.72 & 0.83 & 0.84 \\
\hline & MRE (\%) & 64.76 & 51.90 & 51.24 \\
\hline & $\begin{array}{c}\text { RMSE } \\
\left(\mathrm{m} \mathrm{s}^{-1}\right) \\
\end{array}$ & 5.48 & 4.51 & 4.44 \\
\hline \multirow{3}{*}{ The weak wind period ( 2200 UTC 22 Oct to 1200 UTC 23 Oct) } & IA & 0.18 & 0.20 & 0.20 \\
\hline & MRE (\%) & 192.03 & 151.24 & 149.26 \\
\hline & $\begin{array}{l}\text { RMSE } \\
\left(\mathrm{m} \mathrm{s}^{-1}\right)\end{array}$ & 7.93 & 6.30 & 6.20 \\
\hline \multirow{3}{*}{$\begin{array}{l}\text { The whole simulation period (0000 UTC } 21 \text { Oct to } 1200 \text { UTC } 23 \\
\text { Oct) }\end{array}$} & IA & 0.72 & 0.83 & 0.84 \\
\hline & MRE (\%) & 64.75 & 51.89 & 51.24 \\
\hline & $\begin{array}{l}\text { RMSE } \\
\left(\mathrm{m} \mathrm{s}^{-1}\right)\end{array}$ & 5.48 & 4.51 & 4.44 \\
\hline
\end{tabular}

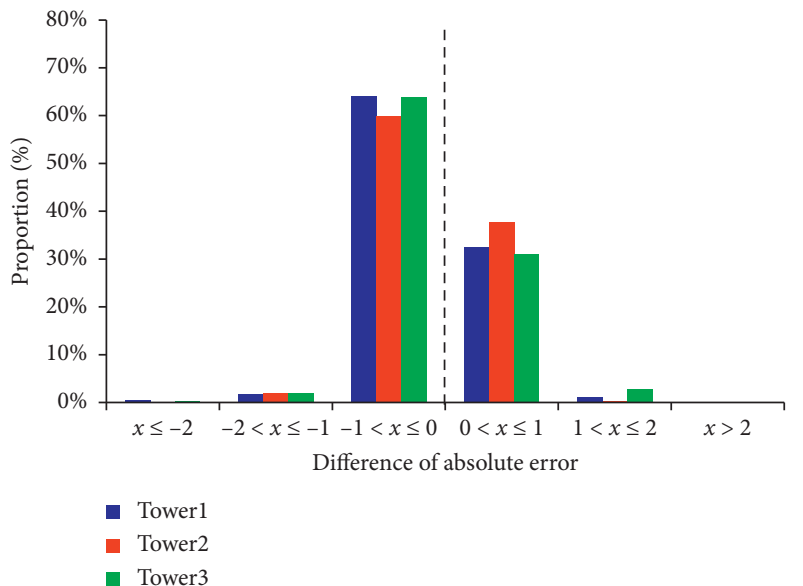

(a)

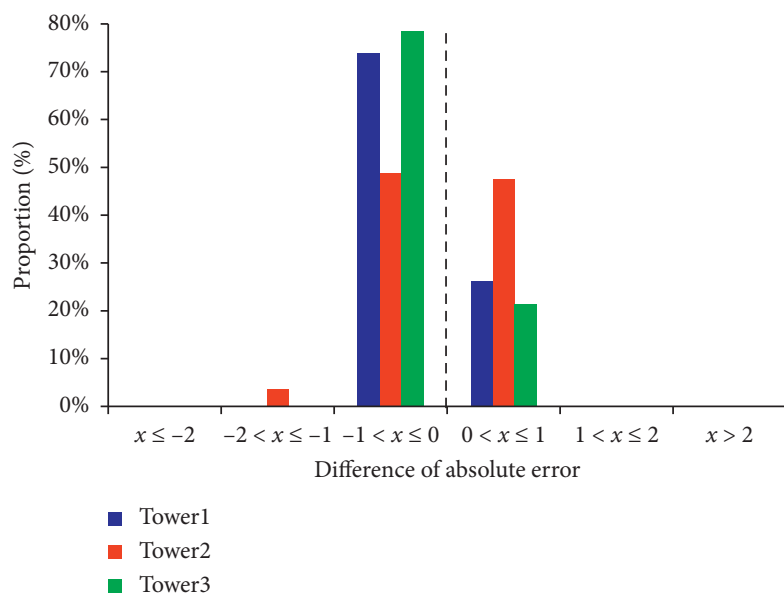

(c)

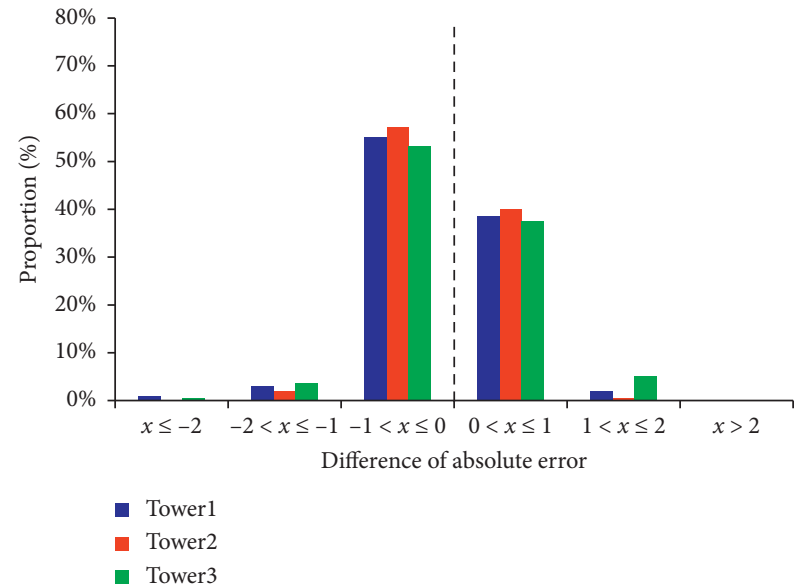

(b)

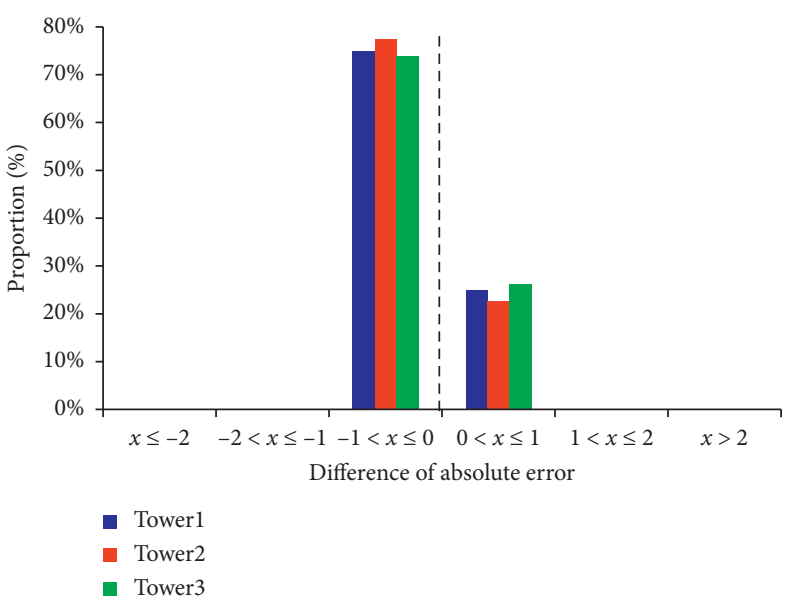

(d)

FIGURE 8: The proportion distribution (unit: \%) regarding the difference of absolute error of near-surface wind speed simulation between $\mathrm{WRF}+3 \mathrm{DVAR}+\mathrm{CALMET}$ and WRF + 3DVAR (WRF + 3DVAR + CALMET minus WRF + 3DVAR) for (a) the whole simulation period (0000 UTC 21 Oct to 1200 UTC 23 Oct), (b) the severe wind period (0000 UTC 21 Oct to 0800 UTC 22 Oct), (c) the severe wind decay period (0800 UTC 22 Oct to 2200 UTC 22 Oct), and (d) the weak wind period (2200 UTC 22 Oct to 1200 UTC 23 Oct). The negative values represent smaller simulation biases in WRF + 3DVAR + CALMET than in WRF + 3DVAR. The zero scale is denoted by black dashed line. 


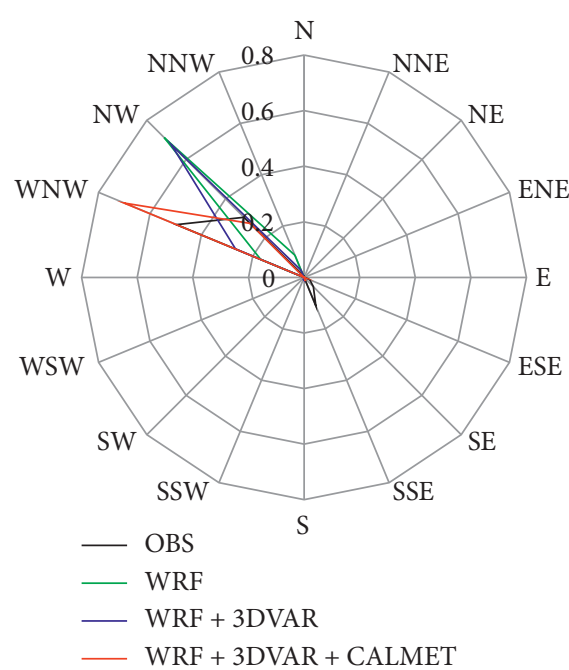

(a)

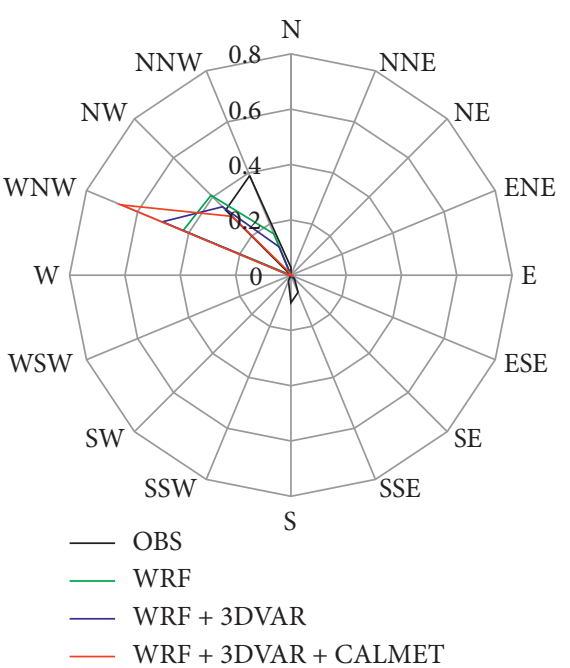

(b)



(c)

FiguRE 9: Comparison of near-surface wind directions at $70 \mathrm{~m}$ for the whole simulation period in different numerical experiments: (a) Tower 1; (b) Tower 2; (c) Tower 3. The numbers in each circle (0 to 0.8$)$ represent the probability of wind directions.

compared to other experiments. Namely, CALMET downscaling simulates the dominant wind directions in Towers 1 and 3 that are similar to the observations (WNW), while other two experiments wrongly simulate as northwest (NW) direction. These indicate that the CALMET has better performance on the simulation of near-surface wind directions than other experiments.

To further compare the local microtopography and illustrate its effects on the simulation of near-surface wind direction, results at 1200 UTC 21 Oct when near-surface wind is strong, 0100 UTC 23 Oct 2010 when near-surface wind decays, and 1100 UTC 23 Oct when near-surface wind is weak are available in Figure 10. Results indicate that the CALMET model provides more refined microtopography structures than the WRF model in the vicinity of the wind towers. In addition, the simulation of near-surface wind directions is comparable in $\mathrm{WRF}+3 \mathrm{DVAR}$ and $\mathrm{WRF}+3 \mathrm{DVAR}+\mathrm{CALMET}$ experiments under strong wind conditions (Figures 10(a) and 10(b)). During the severe wind decay stage (Figures 10(c) and 10(d)), neither of the simulations captures the observed wind directions because of the large simulation biases as shown in Figure 7. It is noticeable that CALMET downscaling $(\mathrm{WRF}+3 \mathrm{DVAR}+\mathrm{CALMET})$ simulates wind directions that are more similar to observations than WRF + 3DVAR when near-surface wind is weak (Figures 10(e) and 10(f)). For instances, the observed wind direction of Tower 1 is about southeast, which is captured by CALMET downscaling while is wrongly simulated as northeast wind by WRF + 3DVAR; the observed wind direction of Tower 3 is about south, which is captured by CALMET downscaling while is wrongly simulated as east wind by WRF + 3DVAR.

The overall results above indicate that the assimilation of in situ and ATOVS radiance observations, combined with the dynamic downscaling of the CALMET model, can 


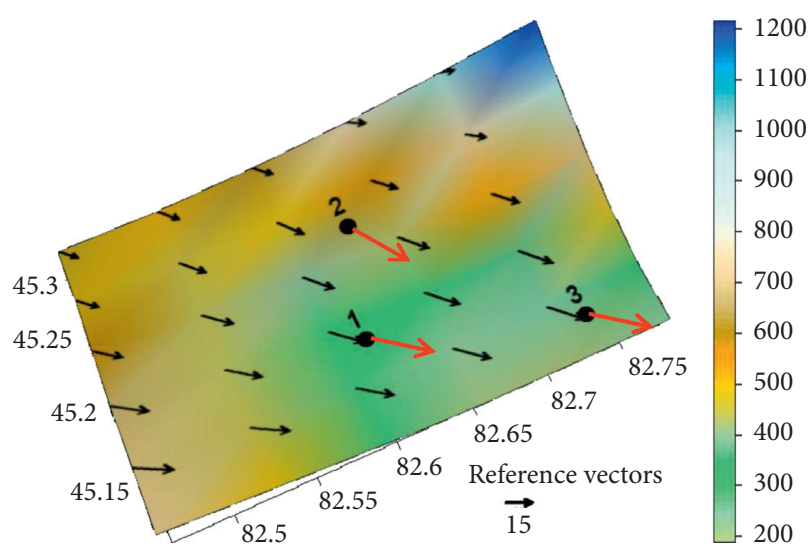

(a)

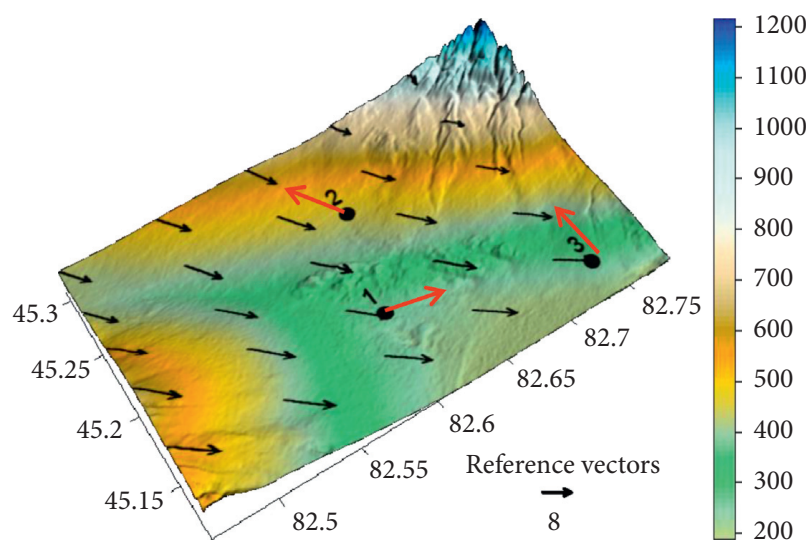

(c)



(e)



(b)

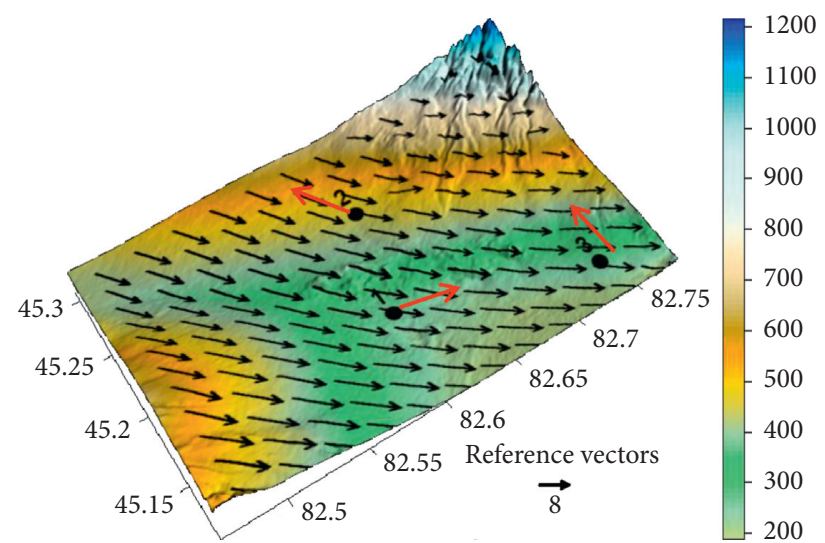

(d)



(f)

Figure 10: Near-surface wind streams (vectors, unit: $\left.\mathrm{m} \mathrm{s}^{-1}\right)$ at $70 \mathrm{~m}$ in (([[parms resize(1),pos(50,50),size(200,200),bgcol(156)]]), (c), (e)) WRF + 3DVAR and ((b), (d), (f)) WRF + 3DVAR + CALMET at ((a)-(b)) 1200 UTC 21 Oct 2010 when near-surface wind is strong, ((c)-(d)) 0100 UTC 23 Oct 2010 when near-surface wind decays, and ((e)-(f)) 1100 UTC 23 Oct 2010 when near-surface wind is weak. The shaded colours denote the terrain topography in the vicinity of the three wind towers in different models. The red and black vectors denote the observed and simulated wind directions.

improve the simulation of both near-surface wind speeds and directions. The evaluation results reveal better dynamic downscaling effects of local microtopography in the CALMET model when near-surface wind is weak, with the downscaling effects mainly manifested in the simulation of wind directions.

\section{Concluding Remarks}

In this study, a severe wind event in the Alataw valley and its vicinity area is selected to investigate the impact of the in situ and ATOVS radiance data assimilation and dynamic downscaling of a microscale meteorological 
diagnostic model (CALMET) on the simulation of nearsurface wind speeds and directions. The main conclusions are as follows:

(1) The assimilation of in situ and ATOVS radiance observations improves the simulation of near-surface wind. Comparison of the initial conditions with and without assimilation indicates that the assimilation produces an obvious airflow across the Alataw valley and triggers the momentum in the upper atmosphere transport downward to the lower atmosphere in the downstream area of the valley. These provide favourable initial dynamic and thermodynamic conditions for the development of severe wind and thus are important to the simulation improvement.

(2) The CALMET model provides much finer local microtopography features than the WRF model. Comparisons between WRF + 3DVAR and $\mathrm{WRF}+3 \mathrm{DVAR}+\mathrm{CALMET}$ indicate that the simulation improvements of near-surface wind speed by CALMET downscaling are mainly within $1 \mathrm{~m} \mathrm{~s}^{-1}$, the mean improvement proportions of near-surface wind speed are $64.8 \%$ for the whole simulation period, $58.7 \%$ for the severe wind period, $68.3 \%$ for the severe wind decay period, and $75.4 \%$ for the weak wind period. These results suggest that the simulation improvements of CALMET downscaling are distinct when near-surface winds are weak. Further evaluation suggests that the downscaling effects of local microtopography in the CALMET are mainly manifested in the simulation of wind directions. The observed near-surface wind directions in the whole simulation period and the observed southeast wind in Tower 1, south wind in Tower 3 when near-surface wind is weak are well captured in coupled model with CALMET downscaling, while are wrongly simulated by WRF and its 3DVAR system.

This study provides an approach to improve the simulation of near-surface wind speeds and directions using various meteorological models and techniques, including the WRF, 3DVAR, and CALMET. The computation cost of CALMET is much cheaper than WRF and 3DVAR assimilation under the same computation configuration. Results of this study are derived based on only one weather case for a short simulation period; our future work will focus on more weather cases with longer simulation period to examine and quantify the detailed added value of near-surface wind simulations contributed by CALMET. Moreover, understanding the mechanisms of the CALMET dynamic downscaling effects, as well as their relation to simulation improvements, will also be focused in our future work based on more in situ and multisource observations. These could be important to researches or real-time forecasts on valley wind circulation, microscale topographic dynamics, wind power exploitation, air pollution prediction, etc., especially over the complex terrain with in situ observations being sparse.

\section{Data Availability}

The GFS real-time forecast data and ATOVS radiance data can be downloaded from ftp://ftp.ncep.noaa.gov/pub/data/ nccf/com/gfs/prod. ERA5 daily reanalysis data can be downloaded from https://cds.climate.copernicus.eu/ \#!/home. The in situ near-surface and sounding observations are provided by the CMA. The wind tower observations near the Alataw valley are available from corresponding author upon request.

\section{Conflicts of Interest}

The authors declare that they have no conflicts of interest.

\section{Acknowledgments}

This study was supported by the Science Foundation of Gansu province in China (20JR5RA309), the National Science Foundation of China (41801019, 41805032, 41975111, 41675098, and 91837205), the National Key Research and Development Program of China (2020YFA0608404), The authors are also grateful for efforts by the National Center for Atmospheric Research (NCAR) in making the community research version of the WRF model available on the public website.

\section{References}

[1] Y. Li, C. Zhang, and X. Gao, "Temporal and spatial characteristics of gale weather over northwest China," Journal of Desert Research, vol. 24, no. 6, pp. 715-723, 2004.

[2] F. Zhang and $\mathrm{Z}$. Pu, "Sensitivity of numerical simulations of near-surface atmospheric conditions to snow depth and surface Albedo during an ice fog event over heber valley," Journal of Applied Meteorology and Climatology, vol. 58, no. 4, pp. 797-811, 2019.

[3] C. Wang, J. Hu, S. Jin, S. Feng, and C. Liu, "Application and test of lower level wind field simulation with mesoscale model WRF in western region of northwest China," Journal of Arid Meteorology, vol. 29, no. 2, pp. 161-167, 2014.

[4] C. Wang, S. Jin, and S. Yang, "Simulation and analysis of the thermal-dynamics characteristics of " 2.28 " severe wind event in Xinjiang with WRF model," Journal of Desert Research, vol. 31, no. 2, pp. 511-516, 2011.

[5] C. Wang and S. Jin, "Error features and their possible causes in simulated low-level winds by WRF at a wind farm," Wind Energy, vol. 17, no. 9, pp. 1315-1325, 2014.

[6] B. Storm, J. Dudhia, S. Basu, A. Swift, and I. Giammanco, "Evaluation of the weather research and forecasting model on forecasting low-level jets: implications for wind energy," Wind Energy, vol. 12, no. 1, pp. 81-90, 2009.

[7] D. R. Stauffer, N. L. Seaman, and F. S. Binkowski, "Use of four-dimensional data assimilation in a limited-area mesoscale model Part II: effects of data assimilation within the planetary boundary layer," Monthly Weather Review, vol. 119, no. 3, pp. 734-754, 1991.

[8] Y. Liu, T. T. Warner, J. F. Bowers et al., "The operational mesogamma-scale Analysis and forecast system of the U.S. Army test and evaluation command. Part I: overview of the modeling system, the forecast products, and how the products 
are used," Journal of Applied Meteorology and Climatology, vol. 47, no. 4, pp. 1077-1092, 2008.

[9] S. E. Carson, G. Wiener, Y. Liu et al., "A wind power forecasting system to optimize power integration," in Proceedings of the ASME 2011 5th International Conference on Energy Sustainability, pp. 2215-2222, American Society of Mechanical Engineers (ASME), Washington, DC, USA, August 2011.

[10] F. Zhang, Y. Yang, and C. Wang, "The effects of assimilating conventional and ATOVS data on forecasted near-surface wind with WRF-3DVAR," Monthly Weather Review, vol. 143, no. 1, pp. 153-164, 2015.

[11] J. Li, H. Geng, P. Xie, and L. Zhang, "Research on the application of fineness method based on WRF-CALMET in gale forecasting," Meteorology, vol. 43, no. 8, pp. 1005-1015, 2017.

[12] S. H. Yim, J. C. Fung, A. K. Lau, and S. C. Kot, "Developing a high-resolution wind map for a complex terrain with a coupled MM5/CALMET system," Journal of Geophysical Research, Atmospheres.vol. 112, no. 5, 2007.

[13] W. C. Skamarock, J. B. Klemp, J. Dudhia et al., A Description of the Advanced Research WRF Version 3, NCAR Technical Note, National Center for Atmospheric Research, Boulder, CO, USA, 2008.

[14] J. S. Kain, "The Kain-Fritsch convective parameterization: an update," Journal of Applied Meteorology, vol. 43, no. 1, pp. 170-181, 2004.

[15] Y.-L. Lin, R. D. Farley, and H. D. Orville, "Bulk parameterization of the snow field in a cloud model," Journal of Climate and Applied Meteorology, vol. 22, no. 6, pp. 1065-1092, 1983.

[16] E. J. Mlawer, S. J. Taubman, P. D. Brown, M. J. Iacono, and S. A. Clough, "Radiative transfer for inhomogeneous atmospheres: RRTM, a validated correlated- $\mathrm{k}$ model for the longwave," Journal of Geophysical Research: Atmospheres, vol. 102, no. 14, pp. 16663-16682, 1997.

[17] J. Dudhia, "Numerical study of convection observed during the winter monsoon experiment using a mesoscale two-dimensional model," Journal of the Atmospheric Sciences, vol. 46, no. 20, pp. 3077-3107, 1989.

[18] S.-Y. Hong, Y. Noh, and J. Dudhia, "A new vertical diffusion package with an explicit treatment of entrainment processes," Monthly Weather Review, vol. 134, no. 9, pp. 2318-2341, 2006.

[19] F. Chen and J. Dudhia, "Coupling an Advanced land surface-hydrology model with the penn state-NCAR MM5 modeling system. Part I: model implementation and sensitivity," Monthly Weather Review, vol. 129, no. 4, pp. 569-585, 2001.

[20] D. F. Parrish and J. C. Derber, "The national meteorological center's spectral statistical-interpolation analysis system," Monthly Weather Review, vol. 120, no. 8, pp. 1747-1763, 1992.

[21] J. S. Scire, F. R. Robe, M. E. Fernau et al., A User's Guide for the CALMET Meteorological Model, Earth Tech, Inc. USA, Land O’Lakes, FL, USA, 2000, http://www.src.com/calpuff/ download/CALMET_UsersGuide.pdf.

[22] A. A. M. Holtslag and A. P. van Ulden, "A simple scheme for daytime estimates of the surface fluxes from routine weather data," Journal of Climate and Applied Meteorology, vol. 22, no. 4, pp. 517-529, 1983.

[23] F. H. GandinDeaven, K. D. Sashegyi, R. V. Madala, and S. Raman, "The use of surface observations in four-dimensional data assimilation using a mesoscale model," Monthly Weather Review, vol. 124, no. 5, pp. 1018-1033, 1996.
[24] Z. Xu, J. Gong, J. Wang, and Z. Li, “A study of assimilation of surface observational data in complex terrain Part I: influence of the elevation difference between model surface and observation site," Chinese Journal of Atmospheric Sciences, vol. 31, no. 2, pp. 222-232, 2007.

[25] Z. Pu, H. Zhang, and J. Anderson, "Ensemble Kalman filter assimilation of near-surface observations over complex terrain: comparison with 3DVAR for short-range forecasts," Tellus A: Dynamic Meteorology and Oceanography, vol. 65, no. 1, p. 19620, 2013. 